\title{
HEALTH DETERM INANTS IN ITALIAN TYPE 2 DIABETES MELLITUS (T2DM) PATIENTS: A CRITICAL GENDER DIFFERENCES ANALYSIS
}

\author{
ROSARIO CARUSO \\ rosario.caruso@grupposandonato.it \\ Health Professions Research and Development Unit, \\ IRCCS Policlinico San Donato \\ (corresponding author) \\ CRISTINA ARRIGONI \\ cristina.arrigoni@unipv.it
}

Department of Public Health, Experimental and Forensic Medicine,

Section of Hygiene,

University of Pavia

ARIANNA MAGON

arianna.magon@grupposandonato.it

Health Professions Research and Development Unit,

IRCCS Policlinico San Donato

FRANCESCO PITTELLA

francesco.pittella@grupposandonbato.it

Health Professions Research and Development Unit,

IRCCS Policlinico San Donato

FEDERICA DELLAFIORE

federica.dellafiore@grupposandonato.it

Health Professions Research and Development Unit

IRCCS Policlinico San Donato

ANNA MARIA GRUGNETTI

anna.grugnetti@unipv.it

Fondazione IRCCS Policlinico San Matteo Pavia

DAVIDE AUSILI

davide.ausili@unimib.it

Department of Medicine and Surgery,

University of Milano-Bicocca

FRANCESCO AUXILIA

francesco.auxilia@unimi.it

Department of Biomedical Science for Health,

University of Milan 
ABSTRACT. Different studies described the important role of wellbeing, self-care and self-efficacy (i.e. health determinants) to achieve best health outcomes in Type 2 Diabetes Mellitus (T2DM) patients. However, literature has paid little attention to highlight the possible gender differences related to the T2DM perception of those health determinants. For these reason, the aim of this study was to describe T2DM patients' gender differences related to their wellbeing, self-care and self-efficacy. This study was performed by a secondary analysis of data from a cross-sectional research, conducted in an outpatient setting in Northern Italy. Data was collected from March 2014 and July 2016 in a cohort of 115 T2DM outpatients, aged from 60 to 91 years (mean $=69.78 \pm 7.11)$. Our results showed that men perceived more general wellbeing than women, and more diabetes specific self-efficacy. No differences seemed to be related to self-care. Indeed, the stratification by gender of the bivariate analysis allowed to identify many peculiarities related to wellbeing domains and self-efficacy. This study had a pioneering nuance in Italian assessment of T2DM health determinants, and it could have a number of future implications. Further empirical researches should provide more information to deeply understand the T2DM patients' peculiarities, which could help nurses to improve a personalized care delivery.

Keywords: diabetes; gender differences; nursing; self-care; self-efficacy; well-being

How to cite: Caruso, Rosario, Cristina Arrigoni, Arianna Magon, Francesco Pittella, Federica Dellafiore, Anna Maria Grugnetti, Davide Ausili, and Francesco Auxilia (2017). "Health Determinants in Italian Type 2 Diabetes Mellitus (T2DM) Patients: A Critical Gender Differences Analysis," Journal of Research in Gender Studies 7(2): 93-108.

Received 25 August $2017 \cdot$ Received in revised form 6 September 2017 Accepted 6 September 2017 • Available online 27 September 2017

\section{Introduction}

World Health Organization (WHO) estimated that Type II Diabetes Mellitus (T2DM) is the third highest risk factor for premature mortality worldwide, preceded only by the high blood pressure and the tobacco use (WHO, 2009). According to the latest report of International Diabetes Federation (IDF), the T2DM prevalence increases every year. In fact, 415 million people worldwide (8.8\% of adults aged between 20-79) have diabetes, estimating an increasing to 642 million people, where the ratio will be 1:10 among adult population within the 2040 (IDF, 2015). For this reason, T2DM is one of the largest global health challenge of the $21^{\text {st }}$ century (IDF, 2015).

Considering the T2DM epidemiology, men present higher T2DM prevalence than women, in fact men with T2DM are 215.2 million, while the women are 199.5 million (IDF, 2015). The T2DM prevalence is also increasing by 2040 , estimating that men will be 328.4 million, while women will be 313.3 million (IDF, 2015). Those epidemiological gender differences are also shown by the Italian population T2DM distribution, considering that 
Italian men with $\mathrm{T} 2 \mathrm{DM}$ are $6.6 \%$ of the overall population, while Italian women are 5.9\% (ARNO, 2015). Despite these epidemiological differences, there are few evidence showing the possible gender differences among T2DM patients, especially related to their perceptions of the most common T2DM health determinants, such as wellbeing, self-care and self-efficacy (Ausili et al., 2016).

\section{Health Determinants in T2DM Patients: Wellbeing, Self-care and Self-efficacy}

T2DM burden is strongly associated to a worsen overall patients' wellbeing (Huang et al., 2007), where it is typically defined to be "a multidimensional construct that refers to an optimal psychological functioning and a healthy perceived feelings" (Ryan \& Deci, 2001). Furthermore, findings from some studies showed a relationship between wellbeing and health, describing how wellbeing is a protective factor for the overall health (Ryff et al., 2004). Wellbeing is a very important health determinant, due to it also seems to reduce the insurgence risk of chronic diseases, such as cancers (Caruso et al., 2013) or cardiovascular morbidities (Magon et al., 2016).

Another key health determinant is given by the patients' self-care (Riegel et al., 2012). It is closely linked to every patients' health behaviors, influencing significantly the clinical trajectory of T2DM patients (Gao et al., 2013). According to Riegel et al. (2012), self-care was defined "as a natural process of maintaining health through health promoting practices and managing illness," and it could be performed by both healthy and illness patients. Many authors argued that self-care plays a strategic role even in developing the clinical standards for T2DM patients' management and education, from the national to the international levels (Arrigoni et al., 2012; Caruso et al., 2015; Haas et al., 2013). Indeed, the middle-range theory of self-care of chronic illness allows to develop theory-guided educational interventions for patients and their caregivers (Riegel et al., 2012). In this scenario, a recent metaanalysis showed how this kind of interventions has a positive effect on glycaemic control, knowledge and self-efficacy of T2DM patients (Zhao et al., 2017).

T2DM patients' behaviors, such as their self-care, is also predicted by their self-efficacy (Bohanny et al., 2013). Self-efficacy is defined as the perception of person's ability to successfully perform a task (Bandura, 1977), and it seems to mediate the relationship between knowledge and behavior, making a difference in people's actions and thoughts (Bandura, 1977; Caruso et al., 2016; Haas et al., 2013). Therefore, self-efficacy plays a paramount role in delivering a tailored care, considering that an improvement of patients' selfefficacy could enhance their answer to cope with their disease burden (Haas 
et al., 2013). Moreover, empirical evidence among T2DM patients showed that self-efficacy positively predicts their glycaemic control, even in T2DM patients with cognitive impairment (Wykes et al., 2016). A similar evidence was also recently described within the heart failure population, where the self-efficacy (i.e. self-care confidence) totally mediated the relationship between patients' simple attention and their self-care, and between their working memory and their self-care (Vellone et al., 2016). For this reason, it could be argued that health interventions addressing self-efficacy could be more effective than interventions based on cognitive training to improve patients' behaviors.

Generally, different studies described the important role of health determinants to achieve the best health outcomes in T2DM patients, such as the role of wellbeing (Nicolucci et al., 2004), self-care and self-efficacy (King et al., 2010). Health determinants play a key role in predicting a better glycemic control and overall wellbeing (Zhao et al., 2017). Even considering the diverse T2DM epidemiology in its gender stratification, at a worldwide level, but also at an Italian level (ARNO, 2015), there are few evidence highlighting the possible gender differences in health determinants patients' perception.

\section{Purpose}

Despite the important role of health determinants to achieve the best health outcomes in T2DM patients, there is very few evidence highlighting the possible gender differences in health determinants patients' perception by patients. This lack of evidence could have an impact on the care delivery, due to clinicians have poor elements to personalize their care plans, considering the main gender differences, and to assess an evidence-based education. This scenario is also emphasized by the heterogeneity of the T2DM epidemiology in its gender stratification, at a worldwide level, but also at an Italian context (ARNO, 2015).

For this reason, the aim of this study is to describe the T2DM patients' gender differences related to their wellbeing, self-care and self-efficacy (i.e. their main health determinants). According to the empirical evidence (e.g., King et al., 2010; Vellone et al., 2016), and to best answer to this study research aim, the authors set the following hypotheses:

H1: Men perception of wellbeing is higher than in women

H2: Men have higher perception of self-efficacy than women

H3: There are no significant gender differences related to self-care

$\mathrm{H} 4$ : There are gender differences, considering the bivariate relationships between wellbeing, self-care and self-efficacy. 


\section{Methods}

\section{Study Design and Sample}

This study was performed by a secondary analysis of data from a crosssectional study, conducted in an outpatient setting in Northern Italy (Caruso et al., 2015). The parental study details were published elsewhere, and it was aimed (a) to describe the relationship between self-care, self-efficacy, wellbeing and health perception in Italian patients with T2DM and (b) to describe the relations between T2DM patients' lifestyle and cognitive decline (Caruso et al., 2015). Moreover, the Institutional Review Board of the center approved the study before data collection (prot. PSD/n/822).

Considering the parental study, data collection took place during outpatients' visits to diabetes center. After that participants have signed a written informed consent document. All data collection was performed and monitored by two trained nurses, and all the enrolled patients in the parent study were over 60 years of age, with a confirmed diagnosis of T2DM. The period of data collection was between March 2014 and July 2015. In order to extract the patients for this study, the authors set the following exclusion criteria: (a) patients with a severe disease other than T2DM (e.g. advanced cancers, heart failure over than II NYHA, chronic obstructive pulmonary disease, psychiatric disease, coronary event in the last three months); (b) recent diagnosis of T2DM (i.e. less than 6 months); (c) moderate or severe cognitive impairment, assessed using Mini Mental State Examination (MMSE), adjusted for age and literacy (Tombaugh \& McIntyre, 1992). After the application of these exclusion criteria, a convenience sample of 150 T2DM patients was selected and assessed using a robust sensibility test (Ding \& VanderWeele, 2016) to check and control possible confounding variables that may undermine the validity of inferences within this study. Those selected patients $(n=150)$ represented the patients enrolled for this study.

\section{Instruments}

The following instruments were used by the research team to collect the data.

Sociodemographic domain. This section was designed by the research team, and it was in line with the sociodemographic collection of recent studies among T2DM patients (Ausili et al., 2016). The items collected were related to nationality, marital status, education, employment, tobacco use, age, Body Mass Index (BMI), years from diagnosis of T2DM and glycated hemoglobin (Hb1 Ac).

WHO-Wellbeing questionnaire (WBQ). This self-report questionnaire was validated into Italian by Nicolucci et al. (2004). It provides an assessment of four domains related to the wellbeing, giving an overall wellbeing score (WBQ_Tot). WBQ domains are: depression (6 items), anxiety (6 items), 
energy (4 items) and positive wellbeing ( 6 items). Each item is scored using Likert measurements from zero to three ( 0 = "not at all"; 3 = "all the time"). To compute WBQ total score, it is necessary to revise the items related to the anxiety and depression domains, and to sum each item (Nicolucci et al., 2004).

General self-efficacy (GSE). This questionnaire was validated into Italian by Scholz et al. (2002), and it is based on the general self-efficacy theorization of Schwarzer \& Jerusalem (1995). While self-efficacy is commonly described to be situation-specific (Bandura, 1977), some authors conceptualize selfefficacy in a broader way (Caruso et al., 2016; Scholz et al., 2002), defining the general self-efficacy as "the one's confidence in coping with their daily hassles" as well as their adaptation after experiencing all kinds of stressful life events (Scholz et al., 2002; Schwarzer \& Jerusalem, 1995). Hence, GSE measures self-efficacy in its broader sense, and it was a self-report monodimensional scale (10 items), where each item had a response ranging from one (not at all true) to four (exactly true). To compute the GSE total score, the authors suggested to use the mean of the items (Schwarzer \& Jerusalem, 1995).

Diabetes specific Self-efficacy (SE_spec). Talbot et al. (1997) developed a multi-dimensional self-report scale (Multidimensional Diabetes Questionnaire) to assess different domains of T2DM patients, where one domain was specifically developed to measure diabetes specific self-efficacy (Talbot et al., 1997). An Italian validation is available, since 2009 (Lazzari et al., 2009). For this study, only the diabetes specific self-efficacy was taken into account (7 items), and it aims to explore the patients' confidence in coping with their daily diabetes specific activity (e.g., how confident are you in your ability to test your blood sugar at the recommended frequency?). The diabetes specific self-efficacy responses were rated on a zero (not at all confident) to 100 (very confident) rating scale, according to Bandura indication to develop selfefficacy scales (Bandura, 1977). To compute the diabetes specific self-efficacy total score, the authors suggested using the mean of these seven items.

Summary of Diabetes Self-Care Activities (SDSCA). SDSCA is a brief self-report scale, aimed to assess the self-care in diabetes patients (Toobert \& Glasgow, 1994). It was recently validated into Italian (Ausili et al., 2015), and it consists in 11 items, measuring different self-care aspects (i.e., general diet, specific diet, exercise, medication taking, blood-glucose testing, foot care and smoking). Despite the solid evidence on SDSCA reliability (Toobert et al., 2000), there were few evidence related to its psychometric structure (i.e. construct validity). For this reason, in order to be more prudent considering SDSCA in this study analysis, the authors decided to use only the self-care total score and not the single self-care aspects of the scale. To compute the self-care total score, it was needed to sum the first ten items, but revising the 
scoring of the item four, and subtracting one point for each declared smoked cigarette (Ausili et al., 2015).

\section{Data analysis}

This secondary analysis was carried out testing four hypotheses, following the main study aim. Previously, the data (each single included item) were checked using the frequency distribution to assess possible missing, errors or outliers. The computes to measure the different constructs from the questionnaires' items were performed according to the authors of references. Descriptive statistics was used to describe the sample characteristics, where categorical data were presented as frequencies, and continuous data were presented as means \pm standard deviation $(\mathrm{M} \pm \mathrm{SD})$ for normally distributed variables, and as median \pm interquartile range $\left(25^{\circ}-75^{\circ}\right.$ percentile) for continues data non-normally distributed.

The study of skewness was used to preliminary assess the normal distribution of the variables, followed by the Kolmogorov-Smirnov test. The missing data were managed by using a pairwise approach. The sample characteristics were compared between groups (male versus women) using (a) Pearson's $X^{2}$ tests for dichotomous variables in the univariate analysis, where Bonferroni multiple testing correction was used to control for error effects, and (b) using The Student's t-test for parametric values. Mann-Whitney U test was used to test H1, H2 and H3. The Spearman correlation study was used to test H4. All data were analyzed using Statistical Package for Social Science version 22 (SPSS, Chicago, IL, USA) and Microsoft Excel, and the level of significance of each test was set at 0.05 and two-tailed.

\section{Results}

A total of $150 \mathrm{~T} 2 \mathrm{DM}$ patients with an age range of 60 to 91 years $($ mean $=$ $69.78 \pm 7.11)$ were enrolled in this study. The majority of patients were males $(n=87 ; 58 \%)$, Italians $(n=147 ; 98 \%)$, married $(n=119 ; 79.3 \%)$, with a high school diploma $(n=50 ; 33.3 \%)$ and retired $(n=97 ; 64.7 \%)$. Moreover, $90 \%$ did not smoke $(n=135)$, their BMI was a mean of $27.61 \mathrm{Kg} / \mathrm{m} 2(\mathrm{SD}=$ 4.79), with 12.61 years from their $\mathrm{T} 2 \mathrm{DM}$ diagnosis $(\mathrm{SD}=9.05)$, and with a $\mathrm{Hb} 1 \mathrm{Ac}$ mean of $55.98 \mathrm{mmol} / \mathrm{mol}(\mathrm{SD}=12.76)$. Considering these characteristics, stratified by gender (Table 1), the sample was homogenous (i.e., without significant differences) regarding nationality $(\mathrm{p}=0.137)$, education $(\mathrm{p}=0.100)$, smoking habit $(\mathrm{p}=0.690)$, age $(\mathrm{p}=0.328)$, BMI $(\mathrm{p}=0.061)$, years from diagnosis of diabetes $(\mathrm{p}=0.236), \mathrm{Hb} 1 \mathrm{Ac}(\mathrm{p}=0.384)$. The only significant differences were related to marital status $(\mathrm{p}=0.000)$ and employment $(\mathrm{p}=0.000)$. 
H1: Men perception of wellbeing is higher than in women The wellbeing domains were (a) depression (WBQ_D), (b) anxiety (WBQ_A), (c) energy (WBQ_E), (d) positive wellbeing (WBQ_P), (e) wellbeing total score (WBQ_Tot), and the descriptive statistics are shown in Table 2. WBQ_P $(p=0.001)$ and WBQ_Tot $(p=0.001)$ were higher in men (Table 2 ), while there were not significant differences considering the other wellbeing domains ( $p>0.05)$ (Table2).

H2: Men have higher perception of self-efficacy than women

GSE was not significantly different among men and women $(\mathrm{p}=0.186)$, while diabetes specific self-efficacy was higher in men $(p=0.023)$, as shown in Table 2.

H3: There are no significant gender differences related to self-care

Considering the comparison related to self-care, there were not significant differences related to the gender stratification $(\mathrm{p}=0.784)$.

H4: There are gender differences, considering the bivariate relationships between wellbeing, self-care and self-efficacy

Considering the two matrixes of Spearman correlation (men and women) showed in Table 3, we found some differences. Firstly, only in women WBQ_A (anxiety) had a moderate positive relationship with WBQ_D (depression) $\left(\mathrm{r}_{\mathrm{s}}=+0.317\right.$; $\left.\mathrm{p}<0.05\right)$. Secondly, WBQ_E (energy) presented a negative relationship with WBQ_A (anxiety) in both men $\left(\mathrm{r}_{\mathrm{s}}=-0.282 ; \mathrm{p}<\right.$ $0.01)$ and women $\left(r_{s}=-0.498 ; p<0.01\right)$, but it showed a negative relation with WBQ_D (depression) only in women $\left(\mathrm{r}_{\mathrm{s}}=-0.308\right.$; $\left.\mathrm{p}<0.05\right)$. Thirdly, WBQ_P (positive wellbeing) had a negative relationship with WBQ_D (depression) in both men $\left(\mathrm{r}_{\mathrm{s}}=-0.504 ; \mathrm{p}<0.01\right)$ and women $\left(\mathrm{r}_{\mathrm{s}}=-0.520 ; \mathrm{p}<\right.$ $0.01)$, but only among women it also had a positive relationship with WBQ_E (energy) $\left(r_{s}=+0.302 ; p<0.05\right)$. Fourthly, WBQ_Tot (wellbeing total score) had a negative relationship with WBQ_A (anxiety) in both men $\left(\mathrm{r}_{\mathrm{s}}=-0.447\right.$; $\mathrm{p}<0.01)$ and women $\left(\mathrm{r}_{\mathrm{s}}=-0.463 ; \mathrm{p}<0.01\right)$ and a positive relationship with WBQ_P $\left(\mathrm{r}_{\mathrm{s} \text { MAN }}=+0.690 ; \mathrm{r}_{\mathrm{s} \text { WOMEN }}=+0.542 ; \mathrm{p}<0.01\right)$, but only in men it showed a positive relation with WBQ_E (energy) $\left(\mathrm{r}_{\mathrm{s}}=+0.397\right.$; $\left.\mathrm{p}<0.01\right)$.

While, considering the GSE the only significant differences were related to the positive relationship between the same GSE and WBQ_E (energy) among men $\left(r_{s}=+0.241 ; p<0.05\right)$. Indeed, there were not significant gender differences related to diabetes specific self-efficacy, which was the unique construct in relationship with self-care $\left(r_{\mathrm{s} \text { MAN }}=+0.460 ; \mathrm{r}_{\mathrm{s}}\right.$ wOMEN $=+0.472 ; \mathrm{p}$ $<0.01)$. 


\section{Discussion}

To the best of our knowledge this is the first Italian study focusing on the gender differences' perception related to wellbeing, self-care and self-efficacy in T2DM patients, aged over sixty years. The study sample seems to reflect the over sixty Italian diabetic population, even considering the differences related to marital status and employment, where the women are widower with higher frequency than men, and the same women have higher frequency of unemployment (ARNO, 2015). Moreover, the authors tested four hypotheses, where $\mathrm{H} 1$ and $\mathrm{H} 2$ were only partially accepted, and $\mathrm{H} 3$ and $\mathrm{H} 4$ were accepted.

According to Nicolucci et al.'s (2004) findings, the authors hypothesize that men perceive more wellbeing than women (H1), and that hypothesis is partially confirmed by our study results. In a previous study, which is not focused on describing the T2DM patients' gender differences, but aimed to validate $\mathrm{WBQ}$, it seemed that there were significant differences in all the WBQ domains, even considering that their sample $(n$ patients aged over sixty $=151)$ was comparable to our study sample $(n=150)$ (Nicolucci et al., 2004). Their results showed that men perceive less depression and anxiety than women ( $p$ $<0.000$ ), while men had higher levels of energy, positive and total wellbeing ( $p$ < 0.000) (Nicolucci et al., 2004). Our results differed from that study, due to the differences were not related to the domains of anxiety, depression and energy, but were related only to the domain of positive and total wellbeing $(p=0.001)$. However, even considering the international literature, it seemed that T2DM men perceive less anxiety and depression than women (Chiu \& Wray, 2011; Demmer et al., 2015). Indeed, some evidence coming from United States of America (USA), and tested using structural equation modeling, highlighted how T2DM women showed less functional coping strategies then men (Demmer et al., 2015). Those could be the reasons underpinning the gender differences, considering the level of anxiety and depression, which are higher in women.

Considering self-efficacy, $\mathrm{H} 2$ was partially accepted, due to there were not significant differences regarding the GSE. This could be explained considering the broad sense of GSE, which could be less specific to explain the relationship between disease-specific issues and patients' ability to cope with them. Although, GSE did not show differences, diabetes specific self-efficacy was in line with $\mathrm{H} 2$, where its scoring was higher in men $(\mathrm{p}=0.023)$. That difference was also highlighted in international literature, where diabetes specific self-efficacy was described as follow: (a) as an indirect mediator of the relationship between gender and HbA1c, blood pressure, BMI, and early complications; (b) as a direct mediator of the relationship between gender and physical exercise (Chiu \& Wray, 2011). 
According to some evidence, the authors hypothesized that there were not significant gender differences related to self-care (H3) (Toljamo \& Hentinen, 2001). H3 was accepted by our results, showing no gender differences related to self-care. Even if our results were in line with some studies (Toljamo \& Hentinen, 2001; Toobert et al., 2000), the literature showed diverse results, highlighting some gender differences related to the self-care levels (Bai et al., 2009). Hence, there were no consensus related to this issue, even because the self-care behaviors in T2DM patients were not yet measurable using a theory-driven assessment tool, such as in other important chronic disease (i.e., hearth failure) (Riegel et al., 2012). In other words, it is reasonable that a theory-driven tool aimed to assess the self-care behaviors in T2DM patients should help the understanding of the self-care gender differences, giving some additional implication for clinical practice.

The study of bivariate correlations, stratifying the sample by gender $(\mathrm{H} 4)$ should help the comprehension of which determinants could be useful to best describe the phenomena (i.e., gender differences among T2DM patients). Our highlighted correlations related to gender differences gave some hints for the development of future research frameworks. Hence, gender should be considered a control variable in studies aimed to describe the relationships between wellbeing, self-care and self-efficacy, whenever a multivariate model will be used.

This study had some limitations. The first is given by the study design, being a secondary analysis on a dataset of a previous study data collection. Then, the data collection was cross-sectional, and for this reason we could not have any information about stability of the investigated phenomena and strong inferences were not allowed. Moreover, the sample was referred to a single outpatient setting in Northern Italy, thus results should be generalizable with caution. Despite those limitations, the major study strengths are related to the pioneering description of the health determinates among T2DM Italian patients aged over sixty years, where the study sample well represented T2DM population, considering the broad variance of the investigated health determinants, and even of the glycemic control of those patients (Hb1 Ac).

\section{Conclusions}

Nursing care delivery is mainly characterized by the understanding of patients' needs (Caruso \& Lichosik, 2015; Caruso et al., 2013), and nursing competencies should answer to those needs, due to nurses' competence is performancespecific (Caruso et al., 2016). Within this scenario, the recognition of patients' peculiarities is paramount to determine what should be the results of nurses' performance, where the gender differences in T2DM patients could be important to achieve better outcomes, even considering the diverse gender 
distribution in Italian context. Our results clarify how gender is important to assess a personalized planning for T2DM patients, aged over sixty years and it could have a number of future implications.

Firstly, it is useful to perform a comparison with the international literature as highlighted in the discussion section. Moreover, the authors find some issues related to the above-mentioned comparison, due to there are only few tools to measure T2DM health determinants used as a gold-standard in research and clinical settings, determining a diverse field of knowledge. Our results should help to guide the patients' education, considering some highlighted peculiarities in this study related to T2DM patients' gender differences perception of their wellbeing, self-care and self-efficacy.

Indeed, this study could be useful to hypothesize the mediator role of selfefficacy in the relationship between the characteristics of the T2DM patients (e.g., cognitive ability, age, education level) and their health determinants. For this reason, further empirical researches should provide more information to deeply understand the T2DM patients' peculiarities, which could help nurses to improve a personalized care delivery. The results of our study suggest a deeply understanding of the phenomena using longitudinal study designs, considering some diverse results coming from the literature, and giving many hints for the development of future research frameworks.

More generally, the field of gender differences studies in health promotion and community health should be more represented in empirical research, considering the current imbalance we often find in studies samples (Polit \& Beck, 2013). The implication of the possible gap in knowledge arising from gender differences analysis could have an impact on the optimal management of the major chronic diseases. To best face with all those possible issues, it is recommended a paradigmatic shift when research designs are planned giving more emphasis in considering how gender could impact the research findings.

Consent for publication: Each patients involved in the study have signed a written informed consent document.

Competing interests: No conflict of interest has been declared by the authors.

Funding: This research received no specific grant from any funding agency in the public, commercial, or not-for-profit sectors.

Authors' contributions: RC, CA and FD developed the main idea. FD and FP developed the study protocol and gave a substantial contribution to collect data. AMG screened the citations. RC and AM performed data analysis. DA and FA both contributed to the final version of the paper. All the authors read and approved the final manuscript.

Acknowledgement: A special goes to the two nurses who collected most of the data used in this study, Irene Baroni and Fabio Lo Re. 
Table 1 Sample characteristics, stratified by gender

\begin{tabular}{|c|c|c|c|c|c|c|}
\hline & \multicolumn{2}{|l|}{ MEN } & \multicolumn{2}{|c|}{ WOMEN } & \multirow{2}{*}{$\mathbf{p} \S$} \\
\hline & & $n$ & $\%$ & $n$ & $\%$ & \\
\hline Nationality & $\begin{array}{l}\text { Italian } \\
\text { Other }\end{array}$ & $\begin{array}{l}84 \\
3\end{array}$ & $\begin{array}{l}96.6 \\
3.4\end{array}$ & $\begin{array}{l}63 \\
0\end{array}$ & $\begin{array}{l}100 \\
0\end{array}$ & $0.137^{\mathrm{a}}$ \\
\hline Marital Status & \begin{tabular}{|l} 
Unmarried \\
Married \\
Divorced \\
Widower \\
\end{tabular} & \begin{tabular}{|l|}
5 \\
79 \\
1 \\
2 \\
\end{tabular} & $\begin{array}{l}5.7 \\
90.8 \\
1.1 \\
2.3\end{array}$ & \begin{tabular}{|l|}
2 \\
40 \\
1 \\
20
\end{tabular} & $\begin{array}{l}3.2 \\
63.5 \\
1.6 \\
31.7\end{array}$ & $0.000^{b}$ \\
\hline Education & \begin{tabular}{|l|} 
None \\
Primary school \\
Secondary school \\
High school \\
University \\
\end{tabular} & $\begin{array}{l}0 \\
22 \\
23 \\
33 \\
9 \\
\end{array}$ & $\begin{array}{l}0 \\
25.3 \\
26.4 \\
37.9 \\
10.3 \\
\end{array}$ & \begin{tabular}{|l|}
3 \\
19 \\
21 \\
17 \\
3 \\
\end{tabular} & $\begin{array}{l}4.8 \\
30.2 \\
33.3 \\
27 \\
4.8 \\
\end{array}$ & $0.100^{\mathrm{c}}$ \\
\hline Employment & $\begin{array}{l}\text { Retired } \\
\text { Employed } \\
\text { Freelance } \\
\text { Unemployed }\end{array}$ & $\begin{array}{l}61 \\
21 \\
5 \\
0 \\
\end{array}$ & $\begin{array}{l}70.1 \\
24.1 \\
5.7 \\
0 \\
\end{array}$ & \begin{tabular}{|l|}
36 \\
3 \\
0 \\
24 \\
\end{tabular} & $\begin{array}{l}57.1 \\
4.8 \\
0 \\
38.1 \\
\end{array}$ & $0.000^{\mathrm{d}}$ \\
\hline \multirow[t]{2}{*}{ Smoker } & \begin{tabular}{|l|} 
Yes \\
No \\
\end{tabular} & $\begin{array}{l}12 \\
75 \\
\end{array}$ & $\begin{array}{l}13.8 \\
86.2 \\
\end{array}$ & \begin{tabular}{|l|}
3 \\
60 \\
\end{tabular} & $\begin{array}{l}4.8 \\
95.2 \\
\end{array}$ & $0.690^{\mathrm{e}}$ \\
\hline & & Mean & St. Dev. & Mean & St. Dev. & \\
\hline \multicolumn{2}{|l|}{ Age } & 69.3 & 7.2 & 70.4 & 6.9 & $0.328^{f}$ \\
\hline \multicolumn{2}{|c|}{ BMI } & 27.0 & 4.2 & 28.5 & 5.4 & $0.061^{\mathrm{g}}$ \\
\hline \multicolumn{2}{|c|}{ Years from diagnosis } & 13.3 & 10.5 & 11.7 & 6.6 & $0.236^{\mathrm{h}}$ \\
\hline \multicolumn{2}{|c|}{ Hb1Ac (mmol/mol) } & 55.2 & 12.1 & 57.2 & 13.6 & $0.384^{1}$ \\
\hline
\end{tabular}

Legend:

$\S \mathrm{P}$-values estimated in relation to the nature of the variables, as follow:

${ }^{a}$ Pearson's $X^{2}$ test (2.217); d.f. $=1$

b Pearson's $X^{2}$ test (25.610); d.f. $=3$

' Pearson's $X^{2}$ test (7.790); d.f. $=4$

d Pearson's $X^{2}$ test (46.288); d.f. $=3$

${ }^{\mathrm{e}}$ Pearson's $X^{2}$ test (3.311); d.f. $=1$

${ }^{\mathrm{f}}$ The Student's t-test $(\mathrm{t}=-0.981) ;$ d.f. $=138$

${ }^{\mathrm{g}}$ The Student's t-test $(\mathrm{t}=-1.895) ;$ d.f. $=114$

${ }^{\mathrm{h}}$ The Student's t-test $(\mathrm{t}=1.190) ;$ d.f. $=146$

${ }^{\text {I }}$ The Student's t-test $(t=-0.874) ;$ d.f. $=125$

\# Bonferroni multiple testing correction was used to control for error effects for Pearson's $X^{2}$ test

\#\# All the statistics was performed setting the level of significance at 0.05 
Table 2 T2DM Health Determinants: gender differences

\begin{tabular}{l|lll|lll|l}
\hline & Male & & & Women & \multirow{2}{*}{ \$ } \\
\cline { 2 - 7 } & $25^{\circ}$ pct & median & $75^{\circ}$ pct & $25^{\circ}$ pct & median & $75^{\circ}$ pct & \\
\hline WBQ_D & 1.67 & 1.83 & 2.00 & 1.50 & 1.83 & 2.17 & 0.717 \\
WBQ_A & 0.83 & 1.00 & 1.33 & 0.83 & 1.33 & 1.50 & 0.274 \\
WBQ_E & 1.25 & 1.50 & 1.50 & 1.00 & 1.50 & 1.75 & 0.397 \\
WBQ_P & 2.00 & 2.33 & 3.00 & 1.50 & 2.00 & 2.33 & $\mathbf{0 . 0 0 1}$ \\
WBQ_Tot & 35.00 & 37.00 & 41.00 & 32.00 & 35.00 & 37.00 & $\mathbf{0 . 0 0 1}$ \\
SE_Gen & 2.70 & 3.00 & 3.30 & 2.60 & 2.90 & 3.30 & 0.186 \\
SE_spec & 60.00 & 71.43 & 82.86 & 47.14 & 64.29 & 75.71 & $\mathbf{0 . 0 2 3}$ \\
Self-care & 31.50 & 40.00 & 47.00 & 33.00 & 41.00 & 48.00 & 0.784 \\
\hline
\end{tabular}

Legend:

$\S$ P-values estimated using the Mann-Whitney U test, the level of significance was set at 0.05 (2-tailed)

WBQ_D = Depression; WBQ_A = Anxiety; WBQ_E = Energy; WBQ_P = Positive Wellbeing; WBQ_Tot = Wellbeing Total score GSE= General Self-efficacy; Self-care $=$ Self-care total score; $\mathrm{SE} \_$spec $=$Self-efficacy diabetes-specific

Table 3 Spearman correlations, stratifying the sample by gender

\begin{tabular}{|c|c|c|c|c|c|c|c|c|}
\hline \multicolumn{9}{|l|}{ Men } \\
\hline Constructs & 1 & 2 & 3 & 4 & 5 & 6 & 7 & 8 \\
\hline WBQ_D (1) & - & & & & & & & \\
\hline WBQ_A (2) & -.068 & - & & & & & & \\
\hline WBQ_E (3) & -.003 & $-.282 * *$ & - & & & & & \\
\hline WBQ_P (4) & $-.504 * *$ & -.166 & .149 & - & & & & \\
\hline WBQ_Tot (5) & .037 & $-.447 * *$ & $.397 * *$ & $.690 * *$ & - & & & \\
\hline GSE (6) & $-.335^{* *}$ & -.108 & $.241 *$ & $.413 * *$ & $.374 * *$ & - & & \\
\hline Self-care (7) & .061 & .191 & .056 & .064 & .024 & .136 & - & \\
\hline SE_spec (8) & .192 & -.190 & .042 & $.340 * *$ & $.360 * *$ & $.403 * *$ & $.460 * *$ & - \\
\hline \multicolumn{9}{|l|}{ Women } \\
\hline Constructs & 1 & 2 & 3 & 4 & 5 & 6 & 7 & 8 \\
\hline WBQ_D (1) & - & & & & & & & \\
\hline WBQ_A (2) & $.317 *$ & - & & & & & & \\
\hline WBQ_E (3) & $-.308^{*}$ & $-.498 * *$ & - & & & & & \\
\hline WBQ_P (4) & $-.520 * *$ & .167 & $.302 *$ & - & & & & \\
\hline WBQ_Tot (5) & -.176 & $-.463 * *$ & .146 & $.542 * *$ & - & & & \\
\hline GSE (6) & $-.445^{* *}$ & -.024 & .003 & $.540 * *$ & $.311^{*}$ & - & & \\
\hline Self-care (7) & .023 & .011 & .077 & .242 & .222 & .205 & - & \\
\hline SE_spec (8) & $.282 *$ & .113 & .157 & .184 & .000 & .074 & $.472 * *$ & - \\
\hline
\end{tabular}

Legend:

** Correlation is significant at the 0.01 level (2-tailed)

* Correlation is significant at the 0.05 level (2-tailed)

WBQ_D = Depression; WBQ_A = Anxiety; WBQ_E = Energy; WBQ_P = Positive Wellbeing; WBQ_Tot = Wellbeing Total score

GSE = General Self-efficacy; Self-care = Self-care total score; SE_spec = Self-efficacy diabetes-specific 


\section{REFERENCES}

ARNO (2015). "Rapporto ARNO Diabete 2015." Retrieved December 17, 2016, from http://arno.cineca.it/journal/rassegna-stampa-di-martedi-10-novembre-2015-su-r/

Arrigoni, C., Miazza, D., Gerra, M. T., \& Pelissero, G. (2012). "Prevention in the Workplace and Training of Personnel: New Methodological Approaches," Journal of Preventive Medicine and Hygiene 53(1): 14-19.

Ausili, D., Bezze, S., Cannizzaro, C., Bulgheroni, M., Toolbert, D. J., Genovese, S., \& Mauro, S. Di. (2015). "Valutazione del self-care nelle persone con diabete di tipo 2: traduzione e validazione della Summary of Diabetes Self-Care Activities," Professioni Infermieristiche 68(1): 9-18.

Ausili, D., Rebora, P., Di Mauro, S., Riegel, B., Valsecchi, M. G., Paturzo, M., ... Vellone, E. (2016). "Clinical and Socio-demographic Determinants of Self-care Behaviours in Patients with Heart Failure and Diabetes Mellitus: A Multicentre Cross-sectional Study," International Journal of Nursing Studies 63: 18-27. https://doi.org/10.1016/j.ijnurstu.2016.08.006

Bai, Y.-L., Chiou, C.-P., \& Chang, Y.-Y. (2009). "Self-care Behaviour and Related Factors in Older People with Type 2 Diabetes," Journal of Clinical Nursing 18(23): 3308-3315.

Bandura, A. (1977). Social Learning Theory. 1st edn. Englewood Cliffs, NJ: Prentice Hall.

Bohanny, W., Wu, S.-F. V., Liu, C.-Y., Yeh, S.-H., Tsay, S.-L., \& Wang, T.-J. (2013). "Health Literacy, Self-efficacy, and Self-care Behaviors in Patients with Type 2 Diabetes Mellitus," Journal of the American Association of Nurse Practitioners 25(9): 495-502. https://doi.org/10.1111/1745-7599.12017

Caruso, R., Fida, R., Sili, A., \& Arrigoni, C. (2016). "Towards an Integrated Model of Nursing Competence: An Overview of the Literature Reviews and Concept Analysis," Professioni Infermieristiche 69(1): 35-43. https://doi.org/10.7429/ pi.2016.691035

Caruso, R., \& Lichosik, D. (2015). "Nursing Highlights from the 2015 European Cancer Congress (ECCO18-ESMO40), 25-29 September 2015, Vienna: Reinforcing Multidisciplinarity," Ecancermedicalscience 9: 589. https://doi.org/ 10.3332/ecancer.2015.589

Caruso, R., Pasquale, C. Di, Lichosik, D., Dellafirore, F., \& Pittella, F. (2013). "Report on the 2013 European Multidisciplinary Cancer Congress-ECC 17, Amsterdam, 27 September-1 October 2013: Nursing Highlights," Ecancermedicalscience 7: 367. https://doi.org/10.3332/ecancer.2013.367

Caruso, R., Pittella, F., Zaghini, F., Fida, R., \& Sili, A. (2016). "Development and Validation of the Nursing Profession Self-Efficacy Scale," International Nursing Review 63(3): 455-464. https://doi.org/10.1111/inr.12291

Caruso, R., Santucci, A., Caruso, M. P., Pittella, F., Dellafiore, F., Corbetta, S., \& Mosconi, E. (2015). "Physical Activity, Dietary Habits and Cognitive Decline in over 65 Years Italian Outpatients with Type 2 Diabetes: A Cross-sectional Pilot Study," International Diabetes Nursing 12(2): 69-73. https://doi.org/10.1179/ 2057332415Y.0000000005 
Chiu, C.-J., \& Wray, L. A. (2011). "Gender Differences in Functional Limitations in Adults Living with Type 2 Diabetes: Biobehavioral and Psychosocial Mediators," Annals of Behavioral Medicine 41(1): 71-82. https://doi.org/10.1007/s12160010-9226-0

Demmer, R. T., Gelb, S., Suglia, S. F., Keyes, K. M., Aiello, A. E., Colombo, P. C., ... Kubzansky, L. D. (2015). "Sex Differences in the Association between Depression, Anxiety, and Type 2 Diabetes Mellitus," Psychosomatic Medicine 77(4): 467-77. https://doi.org/10.1097/PSY.0000000000000169

Ding, P., \& VanderWeele, T. J. (2016). "Sensitivity Analysis without Assumptions," Epidemiology 27(3): 368-377. https://doi.org/10.1097/EDE.0000000000000457

Gao, J., Wang, J., Zheng, P., Haardörfer, R., Kegler, M. C., Zhu, Y., \& Fu, H. (2013). "Effects of Self-care, Self-efficacy, Social Support on Glycemic Control in Adults with Type 2 Diabetes," BMC Family Practice 14(1): 1090-1101. https://doi.org/10.1186/1471-2296-14-66

Haas, L., Maryniuk, M., Beck, J., Cox, C. E., Duker, P., Edwards, L., ... Hanson, L. (2013). "National Standards for Diabetes Self-management Education and Support," Diabetes Care 36(S1): S100-S108. https://doi.org/10.2337/dc13-S100

Huang, E. S., Brown, S. E. S., Ewigman, B. G., Foley, E. C., \& Meltzer, D. O. (2007). "Patient Perceptions of Quality of Life with Diabetes-related Complications and Treatments," Diabetes Care 30(10): 2478-2483.

IDF (2015). IDF Diabetes Atlas. 7th edn. Retrieved May 4, 2017, from http:// www.diabetesatlas.org/

King, D. K., Glasgow, R. E., Toobert, D. J., Strycker, L. A., Estabrooks, P. A., Osuna, D., \& Faber, A. J. (2010). "Self-efficacy, Problem Solving, and SocialEnvironmental Support Are Associated with Diabetes Self-Management Behaviors," Diabetes Care 33(4): 751-753.

Lazzari, D., Pisanti, R., Marini, C. G., \& Fatati, G. (2009). "Il Multidimensional Diabetes Questionnaire (MDQ): analisi fattoriale confermativa e proprietà psicometriche della traduzione italiana," Italian Journal of Cognitive and Behavioural Psychotherapy 15(2): 171-188.

Magon, A., Dellafiore, F., Pittella, F., \& Caruso, R. (2016). “Criteri e Requisiti dei percorsi di Self Monitoring per la gestione della Terapia Anticoagulante Orale: analisi meta-narrativa di una revisione sistematica," Ricerca \& Pratica 32(6): 246-254. https://doi.org/10.1707/2492.26100

Nicolucci, A., Giorgino, R., Cucinotta, D., Zoppini, G., Muggeo, M., Squatrito, S., ... Coronel, G. A. (2004). "Validation of the Italian version of the WHO-WellBeing Questionnaire (WHO-WBQ) and the WHO-Diabetes Treatment Satisfaction Questionnaire (WHO-DTSQ)," Diabetes, Nutrition \& Metabolism 17(4): 235-243.

Polit, D. F., \& Beck, C. T. (2013). "Is There Still Gender Bias in Nursing Research? An Update," Research in Nursing \& Health 36(1): 75-83. https://doi.org/10. 1002/nur. 21514

Riegel, B., Jaarsma, T., Strömberg, A., \& Steinbright, E. C. (2012). “A MiddleRange Theory of Self-Care of Chronic Illness," Advances in Nursing Science 3(35): 194-204. https://doi.org/10.1097/ANS.0b013e318261b1ba 
Ryan, R. M., \& Deci, E. L. (2001). “On Happiness and Human Potentials: A Review of Research on Hedonic and Eudaimonic Well-Being," Annual Review of Psychology 52(1): 141-166. https://doi.org/10.1146/annurev.psych.52.1.141

Ryff, C. D., Singer, B. H., \& Dienberg Love, G. (2004). "Positive Health: Connecting Well-being with Biology," Philosophical Transactions of the Royal Society of London. Series B, Biological Sciences 359(1449): 1383-1394. https://doi.org/ 10.1098/rstb.2004.1521

Scholz, U., Doña, B. G., Sud, S., \& Schwarzer, R. (2002). "Is General Self-efficacy a Universal Construct? Psychometric Findings from 25 Countries," European Journal of Psychological Assessment 18(3): 242-251. https://doi.org/10.1027// 1015-5759.18.3.242

Schwarzer, R., \& Jerusalem, M. (1995). "Generalized Self-efficacy Scale," in Weinman, J., Wright, S. \& Johnston, M. (eds.), Measures in Health Psychology: A User's Portfolio. Causal and Control Beliefs. 1st edn. Windsor: NFERNelson, 35-37.

Talbot, F., Nouwen, A., Gingras, J., Gosselin, M., \& Audet, J. (1997). "The Assessment of Diabetes-related Cognitive and Social Factors: The Multidimensional Diabetes Questionnaire," Journal of Behavioral Medicine 20(3): 291-312.

Toljamo, M., \& Hentinen, M. (2001). "Adherence to Self-care and Social Support," Journal of Clinical Nursing 10(5): 618-627. https://doi.org/10.1046/j.13652702.2001.00520.x

Tombaugh, T. N., \& McIntyre, N. J. (1992). "The Mini-mental State Examination: A Comprehensive Review," Journal of the American Geriatrics Society 40(9): 922-935.

Toobert, D., \& Glasgow, R. (1994). "Assessing Diabetes Self-management: The Summary of Diabetes Self-care Activities Questionnaire," in Bradley, C. (ed.), Handbook of Psychology and Diabetes. Chur: Harwood Academic, 351-375.

Toobert, D. J., Hampson, S. E., \& Glasgow, R. E. (2000). "The Summary of Diabetes Self-care Activities Measure: Results from 7 Studies and a Revised Scale," Diabetes Care 23(7): 943-950. https://doi.org/10.2337/diacare.23.7.943

Vellone, E., Pancani, L., Greco, A., Steca, P., \& Riegel, B. (2016). "Self-care Confidence May Be More Important than Cognition to Influence Self-care Behaviors in Adults with Heart Failure: Testing a Mediation Model," International Journal of Nursing Studies 60: 191-199.

WHO (2009). Global Health Risks: Mortality and Burden of Disease Attributable to Selected Major Risks. Bulletin of the World Health Organization. Vol. 87. https://doi.org/10.2471/BLT.09.070565

Wykes, T. L., Lee, A. A., McKibbin, C. L., \& Laurent, S. M. (2016). "Self-Efficacy and Hemoglobin A1C Among Adults with Serious Mental Illness and Type 2 Diabetes," Psychosomatic Medicine 78(3): 263-270. https://doi.org/10.1097/ PSY.0000000000000295

Zhao, F.-F., Suhonen, R., Koskinen, S., \& Leino-Kilpi, H. (2017). "Theory-based Self-management Educational Interventions on Patients with Type 2 Diabetes: A Systematic Review and Meta-analysis of Randomized Controlled Trials," Journal of Advanced Nursing 73(4): 812-833. 